The many stages of carcinogenesis

\section{D.G. Harnden}

Introduction to the Cellular and Molecular Biology of Cancer. Edited by L.M. Franks and N. Teich. Oxford University Press: 1986. Pp.458. Hbk £30, \$59; pbk £15, $\$ 32.50$.

WILL Shakespeare started it: "One man in his time plays many parts". Since then analogies have run rampant. Now Beverly Griffin sees the seven ages of DNA - she does it well, and optimistically forecasts that in the seventh age the intricacies of the normal cell will be unravelled and lead to an understanding of cancer.

Perhaps I should try it - the seven ages of making a cancer textbook. First, the student, perhaps not "mewling and puking", but certainly confused by a subject such as oncology, where the range of disciplines is wide and information has to be picked up from many teachers and often from a variety of courses. Next, the teacher dedicated to a coordinated oncology course. Anyone who has tried, knows the problems. How can you even begin on DNA manipulation unless there is a firm grounding in DNA structure? Yet if you do not take much as read, there is not time to get from DNA to cancer therapy. And then, the brave editor, suggesting that the course should be converted into a book - the students are proferred more detail and time can be devoted to discussions. So distinguished experts send in their contributions, which somehow must be woven into an accurate and readable whole.

Much to their credit, Franks and Teich have succeeded to a large degree where others have totally failed. Their book will be of great value, not only to students but to anyone who wants a broad view of current knowledge of the scientific basis of cancer. The authors are indeed distinguished, the coverage is excellent and the prose very readable.

The groundwork is well laid by Franks himself, while chapters on metastasis and epidemiology ensure that the behaviour of cancer and the scale of the problem are well understood. But the heart of the book deals with carcinogenesis, cellular and molecular processes, and the nature of the cancer cell. The theme of stages set by Griffin recurs throughout the book. Multistage carcinogenesis is universally agreed, but each author sets these stages rather differently. For example, Adam sees radiation carcinogenesis in stages from the physical $\left(10^{-12}\right.$ to $10^{-18}$ seconds) to the cell and tissue stage which lasts months or years. Even growth factors operate in stages, and Waterfield spells them out ion of cell-surface molecules. The editors should also consider the difficult problem of how much background to fill in; some of the contributors expect sophistication of their readers, while others go back to first principles.

So onward to stage five. After that, stage six will be superb, "full of wise saws and modern instances". But what of stage seven? Let me predict - sans page, sans printed word, sans everything, except perhaps a computer terminal.

D.G. Harnden is Director of the Paterson Institute for Cancer Research, Christie Hospital, Wilmslow Road, Manchester M20 9BX, UK.

\section{Death on the Nile}

\section{M. Dixon}

Science in Egyptology: Proceedings of the 'Science in Egyptology' Symposia. Edited by A. Rosalie David. Manchester University Press/Longwood Press: 1986. Pp.525 $£ 45, \$ 77.50$.

IN THE course of excavations in Egypt and Nubia, carried out over several decades about the turn of the century, thousands of mummified and naturally preserved human bodies were recovered, ranging in date from pre-Dynastic times to the Christian period. Unfortunately, because of lack of specialist personnel on the staff of expeditions, the opportunities presented by this material were not fully exploited. With a few notable exceptions, excavators often simply selected for retention and later examination at home those bones which appeared to them to exhibit some abnormality or other point of interest. In general, the remains that did find their way to museums were for the most part neglected for years, during which specimens deteriorated and labels became detached.

Co-operation on any scale between Egyptology, science and medicine was slow in coming, and it was not until the mid-1960s that practical steps were taken to remedy the situation. The appearance of Diseases in Antiquity, edited by D. Brothwell and A.T. Sandison, and published in 1967 by Charles C. Thomas, marked a turning-point, although not all of the papers were concerned with Egypt. Shortly afterwards the work of Chiarelli and his colleagues at Turin, and the foundation of the Paleopathology Association in 1973 through the efforts of Aidan and Eve Cockburn, gave added impetus to interdisciplinary research on life in the ancient Nile Valley.

The Manchester Symposia of 1979 and 1984 have continued and expanded that work, the scope of the latter gathering being widened to include the discussion of techniques applied to pottery and other antiquities. This volume contains a printed record of all the papers presented in 1984, together with a selection of those from 1979. Inevitably, the contributions vary considerably in value, but there is much of interest here. Among the most promising developments is the extraction and cloning in bacteria of DNA from mummified tissue, discussed by S. Pääbo, and the possibilities this offers of determining, among other questions, the genetic relationships between individuals and populations. This is clearly a matter of some importance to scholars grappling, for example, with the complexities of the history of Egypt during the latter part of the Eighteenth Dynasty.

An obstacle in the way of examining mummies has hitherto been the understandable reluctance of museum curators to allow the use of techniques which involve the total or partial destruction of specimens in their care. The application of endoscopy, described by E. Tapp and his colleagues, has changed things almost overnight. It has also permitted the taking of biopsies from such areas as the lungs and the confirmation of diagnoses based on radiological examination.

While the range of techniques discussed in this book is impressive, and augurs well for research on the lives of ancient peoples generally, a note of caution is necessary. There is still a long way to go before Egyptologists can turn to their medical and scientific colleagues with the reasonable expectation of receiving satisfactory answers to their problems. In this regard Renate Germer's closing paper, "Problems of Science in Egyptology" makes salutary reading. As she reminds us, much of the information obtained through the use of methods discussed at the Symposia is at present of limited help to Egyptologists because "a great deal of basic research has yet to be done to determine the applicability of the scientific methods themselves".

D. M. Dixon is a Lecturer in the Department of Egyptology, University College London, Gower Street, London WC1E 6BT, UK. 